\title{
An evaluation of formability using micro-embossing on an ultrafine-grained magnesium AZ31 alloy processed by high-pressure torsion
}

\author{
Jie $\mathrm{Xu}^{1,2, \mathrm{a}}$, Guangnan Xing ${ }^{1,2}$, Debin Shan ${ }^{1,2}$, Bin Guo ${ }^{1,2}$, and Terence G. Langdon ${ }^{3,4}$ \\ ${ }^{1}$ Key Laboratory of Micro-systems and Micro-structures Manufacturing, Ministry of Education, \\ Harbin Institute of Technology, Harbin 150080, China \\ ${ }^{2}$ School of Materials Science and Engineering, Harbin Institute of Technology, Harbin 150001, China \\ ${ }^{3}$ Departments of Aerospace \& Mechanical Engineering and Materials Science, University of \\ Southern California, Los Angeles, CA 90089-1453, USA \\ ${ }^{4}$ Materials Research Group, Faculty of Engineering and the Environment, University of Southampton, \\ Southampton SO17 1BJ, UK
}

\begin{abstract}
An ultrafine-grained (UFG) magnesium AZ31 alloy was achieved with an average grain size of $\sim 200 \mathrm{~nm}$ by high-pressure torsion (HPT) at room temperature (RT) under a pressure of $6.0 \mathrm{GPa}$ through 5 turns. Micro-embossing tests were conducted in a V-groove die having a width of $100 \mu \mathrm{m}$ in the temperature range of 298 to $523 \mathrm{~K}$. The formability of UFG AZ31 alloy was evaluated by measuring the percentage of material flowing into the V-groove. The results show that refinement of grain size can significantly improve the formability by increasing the stain rate sensitivity by comparison with the asdrawn AZ31 alloy. The results demonstrate that the UFG AZ31 alloy exhibits excellent formability for fabricating MEMS components with complicated structures.
\end{abstract}

\section{Introduction}

Micro-forming has become an attractive method to fabricate micro-parts due to its advantageous characteristics for mass production with controlled quality and low cost [1-3]. Fundamental issues relating to materials, processes, tools and machines have been studied intensively in recent years and are well documented in the literature [4-6]. However, the deformation mechanisms at the micro scale may be different from those occurring in conventional metal forming operations due to the so-called size effect in the micro-forming process [7, 8], where size effects are caused mainly by the interactive effect of grain and specimen sizes on the flow stress [9-11]. Therefore, the grain size appears to be the dominant factor which determines the limiting size of the geometrical features that may be fabricated by micro-forming and this means that very small grain sizes, and especially materials having ultrafine grain sizes, are attractive for use in micro-forming operations [12].

\footnotetext{
${ }^{a}$ Corresponding author: xjhit@hit.edu.cn
}

This is an Open Access article distributed under the terms of the Creative Commons Attribution License 4.0, which permits unrestricted use, distribution, and reproduction in any medium, provided the original work is properly cited. 


\section{MATEC Web of Conferences}

Among the processing techniques that may be used for grain refinement, the imposition of severe plastic deformation (SPD) is now well established as an effective process for producing significant grain refinement in polycrystalline metals [13]. At the present time, the most attractive procedures for processing by SPD are equal-channel angular pressing (ECAP) [14] and high-pressure torsion (HPT) [15]. Several investigation show that HPT processing is especially effective in producing materials with submicrometer or even nano-scale grain sizes [16]. By comparison with conventional CG materials, UFG materials have the potential in micro-forming for simultaneously fulfilling two important conditions [17]. First, the average grain size is generally smaller than the smallest dimension of the component and this guarantees reproducible properties. Second, the grain size is sufficiently fine to ensure a high strength and fracture toughness. In addition, a material with very fine grains will exhibit very high ductility and good formability over an appropriate range of temperatures and strain rates [18]. Thus, recent research also demonstrated a potential for using UFG materials for applications in micro-forming at elevated temperatures [12], and some of these UFG materials have been used in the fabrication of miniaturized components [19-22].

However, there remains only limited research on an evaluation of micro formability using microembossing tests on UFG materials. The current study was initiated to produce UFG AZ31 alloy processed by HPT at room temperature, and then formability evaluations were carried out by measuring the percentage of flowed area using a micro V-groove die with a width of $100 \mu \mathrm{m}$ after micro-embossing at an elevated temperature. As will be demonstrated, the experimental results confirm that there is a potential for using UFG AZ31 alloy for applications in production of MEMS components with complicated structures.

\section{Experimental material and procedures}

The experiments were conducted using a commercial AZ31 magnesium alloy supplied in the form of drawn rods having a diameter of $15 \mathrm{~mm}$. Figure 1 shows the microstructure of the as-received drawn condition and it is apparent that the grains are reasonably equiaxed, uniformly distributed and there was an average initial grain size of $\sim 5.4 \mu \mathrm{m}$. The received robs were machined into disks with a diameter of $9.8 \mathrm{~mm}$ and thickness of $1.2 \mathrm{~mm}$. Both sides of these disks were ground using abrasive paper and carefully polished to finial thicknesses of $\sim 0.82 \mathrm{~mm}$. The HPT processing was carried out in quasiconstrained conditions $[23,24]$ at ambient temperature under an applied pressure of $6.0 \mathrm{GPa}$ through 5 turns. One of the disks processed by HPT was ground carefully to a thickness of $70 \mu \mathrm{m}$ and gently thinned by argon ions using Gatan PIPS ion milling at $4.2 \mathrm{kV}$. The microstructure of the sample after HPT processing was observed using a transmission electron microscope (TEM) Tecnai G2 F30.

Following HPT processing, the disks were ground to a thickness of $0.6 \mathrm{~mm}$ and then microembossing samples were cut from the disks with two samples with dimensions of $3.5 \mathrm{~mm}$ in width and $5.5 \mathrm{~mm}$ in length. The samples were situated in off-center positions to avoid possible inhomogeneities near the disk centers. Specifically, the central line of each micro-embossing sample was located at a distance of $2.25 \mathrm{~mm}$ from a line passing through the center of the disk. The location dimensions of the micro-embossing sample in the disk are illustrated in Fig. 2.

To evaluate the microformability of UFG AZ31 alloy, an evaluation system using a micro V-groove die with a width of $100 \mu \mathrm{m}$ and angle of $60^{\circ}$ was developed using YG20 steel material as shown in Fig. 3. The micro-embossing tests were conducted with as-drawn and UFG AZ31 alloy at temperatures ranging from $298 \mathrm{~K}$ to $523 \mathrm{~K}$. In order to avoid the influence of strain rate, a low embossing velocity of $1.0 \times 10^{-3} \mathrm{~mm} / \mathrm{s}$ was adopted and the tests were terminated when the embossing force arrived at $6.5 \mathrm{kN}$. After micro-embossing, the surface shpae of the embossed specimen was measured by a confocal scanning laser microscope (LEXT OLS3000). The filling area $\mathrm{A}_{f}$ was calculated from the measurement data. The filling ratio $R_{f}$ of the filling area $A_{f}$ to the V-groove aera $A_{v}$ was used to evaluate the formability after micro-embossing. 


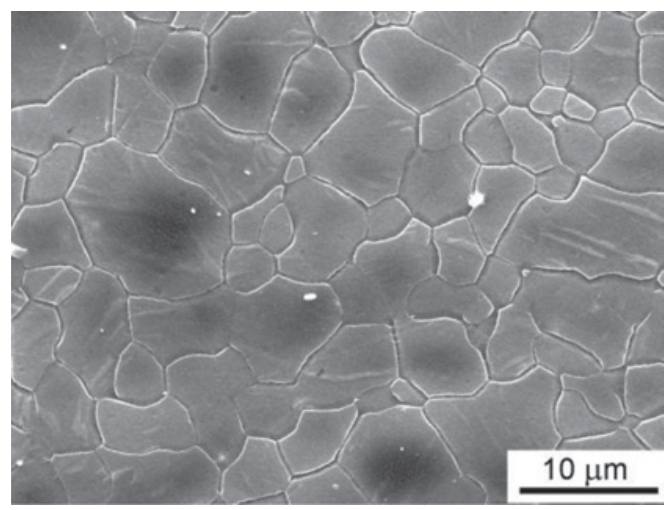

Figure 1. Microstructure of the as-drawn AZ31 magnesium alloy.

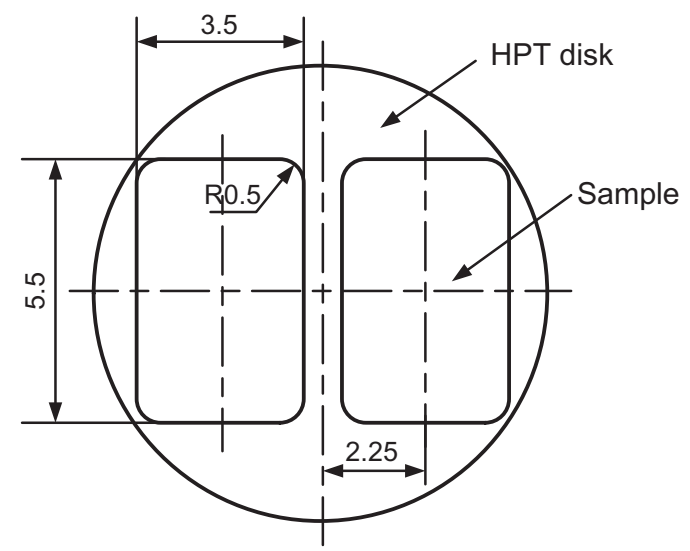

Figure 2. Plan view of an HPT disk showing the locations and dimensions of micro-embossing specimens cut from off-center positions.

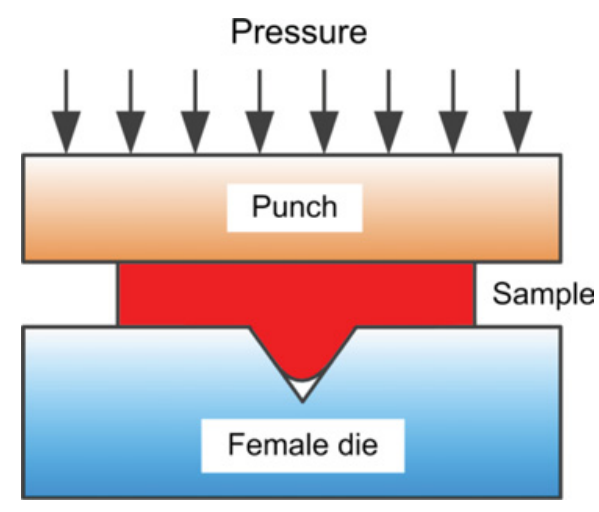

(a) V-groove

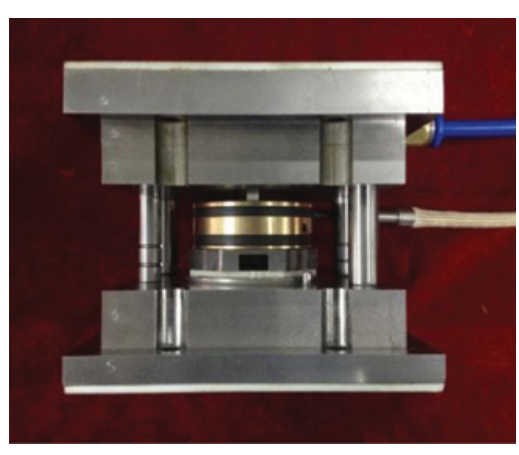

(b) micro-embossing tool

Figure 3. Evaluation system of microformability for UFG AZ31 alloy. 

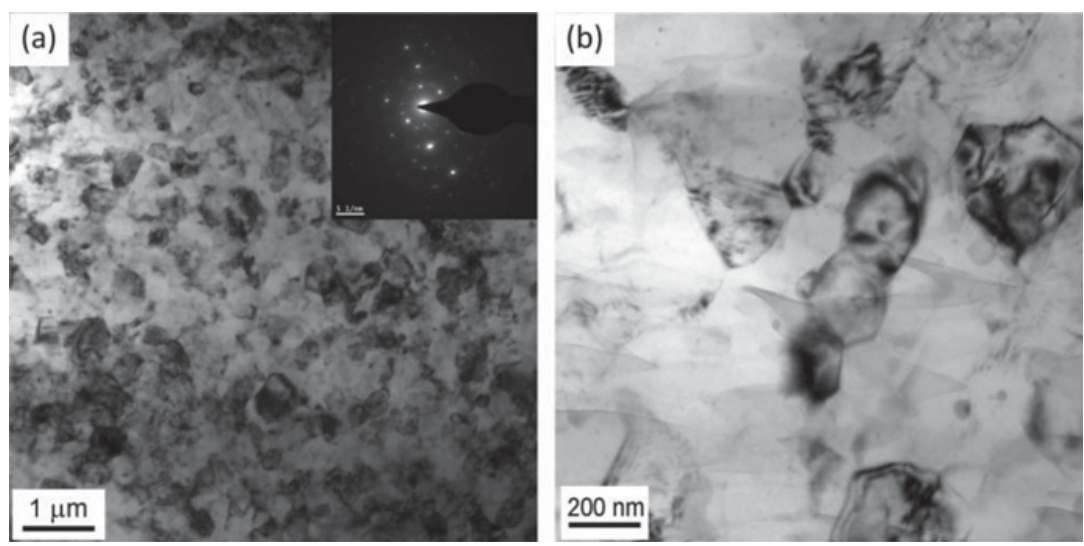

Figure 4. TEM micrographs with (a) low magnification and (b) high magnification in bright-field plus the associated SAED pattern after HPT processing through 5 turns: These images were taken at $\sim 2.5 \mathrm{~mm}$ from the center of the disk.

\section{Experimental results}

\subsection{Microstructure of UFG AZ31 after HPT processing}

Figure 4 shows representative TEM micrographs and a selected area electron diffraction (SAED) pattern for AZ31 alloy processed by HPT through 5 turns, which were observed at $\sim 2.5 \mathrm{~mm}$ from the center of the disk. The bright-field image in Fig. 4a shows clearly the microstructure consists of ultrafinie grains which are well defined. Based on the ring visible in the SAED pattern, these grains are separated by boundaries with high-angles of misorientation. Furthermore, the TEM observation in bright field shows the presence of high densities of dislocation after HPT processing. An average grain size of $\sim 200 \mathrm{~nm}$ was recordes as shown in Fig. 4b after 5 turns, thereby demonstrating a significant grain refinement from the initial annealed grain size of $\sim 5.4 \mu \mathrm{m}$.

\subsection{Formability of UFG AZ31 using micro V-groove die}

Figure 5 shows the filling results after micro-embossing on UFG AZ31 alloy processed by HPT through 5 turns at temperatures ranging from $298 \mathrm{~K}$ to $523 \mathrm{~K}$. The results show that the average filling height increases significantly from $\sim 13 \mu \mathrm{m}$ at ambient temperature to $\sim 95 \mu \mathrm{m}$ and $\sim 98 \mu \mathrm{m}$ at temperatures of $423 \mathrm{~K}$ and $523 \mathrm{~K}$, respectively. The results indicate that the V-groove was filled completely under the embossing force of $6.5 \mathrm{kN}$ when the embossing temperature is more than $423 \mathrm{~K}$. In addition, some materials overflow into the gap due to the split construction in the V-groove die.

Figure 6 shows the filling ratio $R_{f}$ and the standard deviations with increasing of embossing temperature for the as-drawn AZ31 alloy and after HPT processing by HPT through 5 turns. The results demonstrate the different filling behaviour between as-drawn AZ31 alloy and UFG AZ31 alloy processed by HPT. For as-drawn AZ31 alloy, the percentage of flowed area, $R_{f}$, increases slowly with increasing temperature from room temperature to $423 \mathrm{~K}$, and then increases abruptly up to $523 \mathrm{~K}$. In contrast, the filling ratio, $R_{f}$, increases significantly when the embossing temperature in UFG AZ31 is elevated from $298 \mathrm{~K}$ to $423 \mathrm{~K}$, and then continues to increase slowly with increasing of embossing temperature up to $523 \mathrm{~K}$. Calculations showed the average errors on $R_{f}$ at the standard deviation were 6.0, 1.5, 0.5, and 0.1 for UFG AZ31 alloy and 5.5, 6.5, 8.5, and 0.9 for as-drawn AZ31 alloy with increasing of embossing temperature from $298 \mathrm{~K}$ to $523 \mathrm{~K}$, respectively. These calculations suggest that the level of flow homogeneity tends to be improved significantly in the UFG AZ31 alloy. 


\section{ICNFT 2015}

(a)

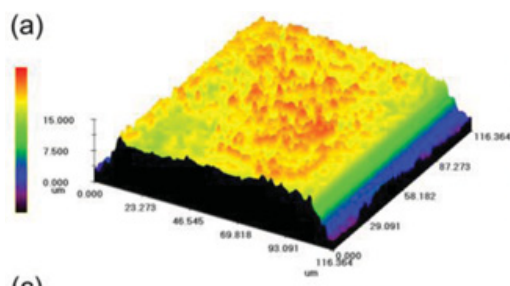

(c)

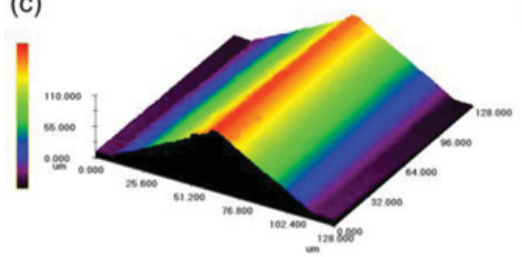

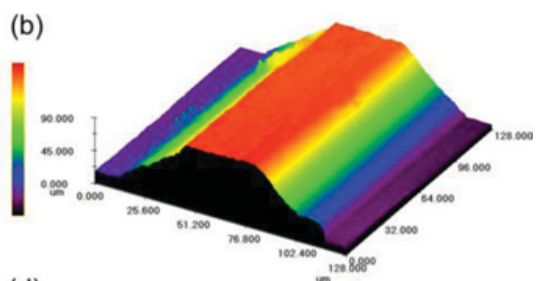

(d)

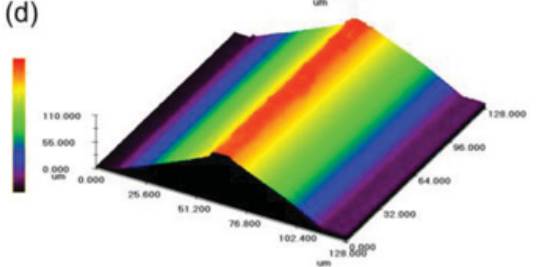

Figure 5. Profile results after micro-embossing on UFG AZ31 alloy at temperatures of (a) $298 \mathrm{~K}$, (b) $423 \mathrm{~K}$, (c) $473 \mathrm{~K}$, and (d) $523 \mathrm{~K}$.

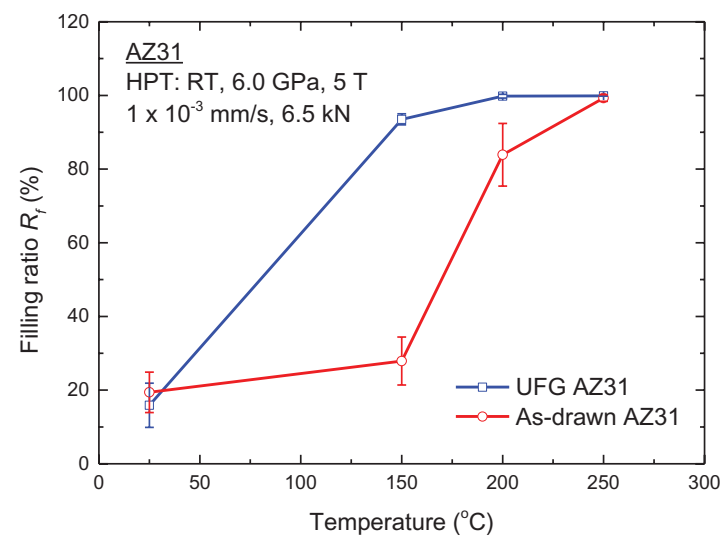

Figure 6. Plots of filling ratio versus the increasing of embossing temperature for UFG AZ31 alloy processed by HPT and as-drawn AZ31 alloy.

\section{Discussion}

UFG AZ31 with an average grain size of $\sim 200 \mathrm{~nm}$ was achieved by HPT processing through 5 turns at room temperature in an as-drawn AZ31 having an initial grain size of $\sim 5.4 \mu \mathrm{m}$. However, an AZ31 alloy with a grain size of $\sim 1.0 \mu \mathrm{m}$ can be obtained by ECAP processing for 8 passes at a temperature of $473 \mathrm{~K} \mathrm{[12]}$. The results demonstrate that processing by HPT can lead to exceptional grain refinement in the AZ31 alloy.

Compared to the as-drawn AZ31 alloy, the percentage of flowed area, $R_{f}$, increases much more quickly in UFG AZ31 alloy processed by HPT with increasing of embossing temperature, which indicates that UFG AZ31 alloy has an excellent formability at lower temperatures during microembossing as shown in Fig. 6. Moreover, the flow behaviour also was improved by homogeneous deformation of ultrafine grains. Similar formability results have been obtained on a micrometer scale for a superplastic $\mathrm{Zn}-22 \mathrm{Al}$ alloy [18]. In this case, the deformation mechanism is dominated with grain boundary sliding and grain rotation [25]. The formability depends on grain size and UFG materials are required to obtain good formability during micro-embossing. 
At present, experiments on UFG pure Al processed by ECAP through 8 passes with an average grain size of $1.3 \mu \mathrm{m}$ confirmed that the geometries and surface quality of the compressed samples can be improved by comparison with coarse-grained pure Al [26]. The UFG pure Al has been successfully applied to fabricate micro-turbine using micro-forming at room temperature [27]. The UFG AZ31 alloy processed by HPT through 5 turns with an average grain size of $200 \mathrm{~nm}$ has excellent formability during micro-embossing using the V-groove die. These results reveal that much more complicated micro-parts can be fabricated with high dimensional accuracy and surface quality using micro-forming technology. In the future, MEMS components with complicated structures will be evaluated using UFG AZ31 alloy processed by HPT.

\section{Conclusions}

[1] A UFG AZ31alloy with average grain size of $\sim 200 \mathrm{~nm}$ was achieved by HPT processing through 5 turns under a pressure of $6.0 \mathrm{GPa}$ at room temperature with an as-drawn alloy having an initial grain size of $\sim 5.4 \mu \mathrm{m}$.

[2] Micro-embossing tests were conducted using a micro V-groove die having a width of $100 \mu \mathrm{m}$ on UFG and as-drawn AZ31 alloy samples. The results show the percentage of flowed area, $R_{f}$, increases more quickly than as-drawn AZ31 with increasing embossing temperature. Moreover, the UFG AZ31 alloy has excellent formability at lower temperatures by comparison with the as-drawn AZ31 alloy.

[3] UFG AZ31 alloy processed by HPT exhibits an excellent micro formability by superplastic deformation, which is expected to become one of most useful materials to fabricate MEMS components with complicated structures.

This work was supported by the National Basic Research Program of China under Grant No. 2012CB934100 and the National Natural Science Foundation of China under Grant No. 51375111. Partial support was provided by the Fundamental Research Funds for the Central Universities under Grant No. HIT. IBRSEM. 201325 and the European Research Council under ERC Grant Agreement No. 267464-SPDMETALS.

\section{References}

[1] M. Geiger, M. Kleiner, R. Eckstein, N. Tiesler, U. Engel, Ann. CIRP 50, 445 (2001)

[2] Y. Qin, J. Mater. Process. Technol. 177, 8 (2006)

[3] Y. Qin, A. Brockett, Y. Ma, A. Razali, J. Zhao, C. Harrison, W. Pan, X. Dai, D. Loziak, Int. J. Adv. Manuf. Technol. 47, 821 (2010)

[4] U. Engel, R. Eckstein, J. Mater. Process. Technol. 125-126, 35 (2002)

[5] F. Vollertsen, H. Schulze Niehoff, Z. Hu, Int. J. Mach. Tools Manuf. 46, 1172 (2006)

[6] M.W. Fu, W.L. Chan, Int. J. Adv. Manuf. Technol. 67, 2411 (2013)

[7] F. Vollertsen, D. Biermann, H.N. Hansen, I.S. Jawahir, K. Kuzman, CIRP Ann. Manuf. Technol. 58, 566 (2009)

[8] J. Xu, B. Guo, D.B. Shan, Int. J. Adv. Manuf. Technol. 56, 511 (2011)

[9] W.L. Chan, M.W. Fu, J. Lu, J.G. Liu, Mater. Sci. Eng. A 527, 6638 (2010)

[10] W.L. Chan, M.W. Fu, Mater. Sci. Eng. A 528, 7674 (2011)

[11] J. Xu, B. Guo, C.J. Wang, D.B. Shan, Int. J. Machine Tools Manuf. 60, 27 (2012)

[12] J. Xu, M. Shirooyeh, J. Wongsa-Ngam, D.B. Shan, B. Guo, T.G. Langdon, Mater. Sci. Eng. A 586, 108 (2013)

[13] R.Z. Valiev, Y. Estrin, Z. Horita, T.G. Langdon, M.J. Zehetbauer, Y.T. Zhu, JOM 58(4), 33 (2006)

[14] R.Z. Valiev, T.G. Langdon, Prog. Mater. Sci. 51, 881 (2006) 


\section{ICNFT 2015}

[15] A.P. Zhilyaev, T.G. Langdon, Prog. Mater. Sci. 53, 893 (2008)

[16] Z. Horita, T.G. Langdon, Mater Sci Eng A 410-411, 422 (2005)

[17] Y. Estrin, M. Janecek, G. I. Raab, R.Z. Valiev, A. Zi, Metall. Mater. Trans. A 381906 (2007)

[18] M.S. Yeh, H.Y. Lin, H.T. Lin, C.B. Chang, J. Mater. Process. Techol. 180, 17 (2006)

[19] L. Olejnik, W. Presz, A. Rosochowski, Int. J. Mater. Form. 2, 617 (2009)

[20] W.J. Kim, Y.K. Sa, Scr. Mater. 54, 1391 (2006)

[21] X. Ma, R. Lapovok, C. Gu, A. Molotnikov, Y. Estrin, E.V. Pereloma, C.H.J. Davies, P.D. Hodgson, J. Mater. Sci. 44, 3807 (2009)

[22] X.G. Qiao, N. Gao, Z. Moktadir, M. Kraft, M.J. Starink, J. Micromech. Microeng. 20, 045029 (2010)

[23] R.B. Figueiredo, P.R. Cetlin, T.G. Langdon, Mater. Sci. Eng. A 528, 8198 (2011)

[24] R.B. Figueiredo, P.H.R. Pereira, M.T.P. Aguilar, P.R. Cetlin, T.G. Langdon, Acta Mater. 60, 3190 (2012)

[25] Y. Saotome, T. Zhang, A. Inoue, Mater. Res. Soc. Symp. Proc. 554, 385 (1999)

[26] J. Xu, C. Wang, D. Shan, B. Guo, T.G. Langdon, Manuf. Rev. 2, 1 (2015)

[27] J. Xu, X. Zhu, L. Shi, D. Shan, B. Guo, T.G. Langdon, Adv. Eng. Mater. (in press) doi: 10.1002 /adem. 201400448 